\title{
Touching and Being in Touch with the Menstruating Body
}

\author{
Nadia Campo Woytuk \\ KTH Royal Institute of Technology \\ Stockholm, Sweden \\ nadiacw@kth.se
}

\author{
Marianela Ciolfi Felice \\ KTH Royal Institute of Technology \\ Stockholm, Sweden \\ ciolfi@kth.se
}

\author{
Marie Louise Juul Søndergaard \\ KTH Royal Institute of Technology \\ Stockholm, Sweden \\ mljso@kth.se
}

\author{
Madeline Balaam \\ KTH Royal Institute of Technology \\ Stockholm, Sweden \\ balaam@kth.se
}

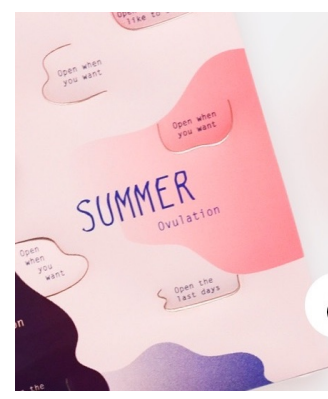

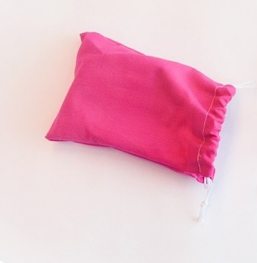

a
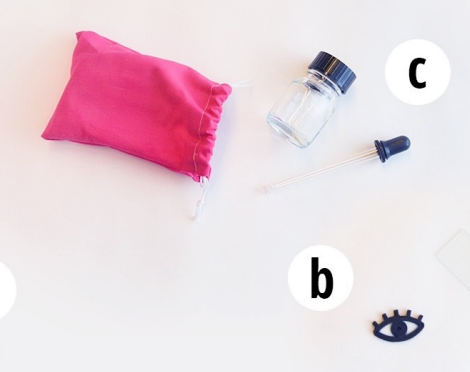

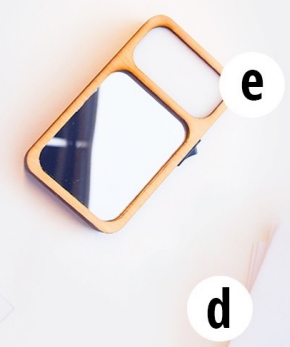

e

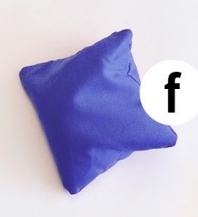

d

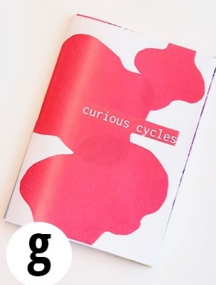

Figure 1. The Curious Cycles kit: (a) The poster, (b) the curious eye, (c) the blood bank, (d) prompts, (e) the reflection, (f) the heat pad, (g) the zine.

\begin{abstract}
We describe a Research through Design project-Curious Cycles-a collection of objects and interactions which encourage people to be in close contact with their menstruating body. Throughout a full menstrual cycle, five participants used Curious Cycles to look at their bodies in unfamiliar ways and to touch their bodily fluids, specifically, menstrual blood, saliva, and cervical mucus. The act of touching and looking led to the construction of new knowledge about the self and to a nurturing appreciation for the changing body. Yet, participants encountered and reflected upon frictions within themselves, their home, and their social surroundings, which stem from societal stigma and preconceptions about menstruation and bodily fluids. We call for and show how interaction design can engage with technologies that mediate self-touch as a first step towards reconfiguring the way menstruating bodies are treated in society.
\end{abstract}

\section{Author Keywords}

Menstrual cycles; research through design; menstruation; feminist HCI; women's health; touching

\footnotetext{
Permission to make digital or hard copies of part or all of this work for personal or classroom use is granted without fee provided that copies are not made or distributed for profit or commercial advantage and that copies bear this notice and the full citation on the first page. Copyrights for third-party components of this work must be honored. For all other uses, contact the owner/author(s).

CHI'20, April 25-30, 2020, Honolulu, HI, USA

(C) 2020 Copyright held by the owner/author(s).

ACM ISBN 978-1-4503-6708-0/20/04 .. \$15.00

DOI: http: //dx.doi.org/10.1145/3313831.3376471
}

\section{CCS Concepts \\ •Human-centered computing $\rightarrow$ Interaction design;}

\section{INTRODUCTION}

We have designed Curious Cycles-a series of objects and interactions - which invite people who menstruate ${ }^{1}$ to experiment with and explore their menstruating body (Fig. 1). These include tools to collect, view and touch menstrual blood ${ }^{2}$, cervical mucus and saliva (Fig. $1 \mathrm{~b}$ and c), a mirror with LED light to enable close inspection of the changing body (Fig. 1e), and a heatable pad to place and feel on the body (Fig. 1f). Throughout one menstrual cycle (approximately one month), we invited five people who menstruate to touch, experiment with, and reflect on their bodies using these objects.

This paper reports on the design of Curious Cycles, and our analysis of participants' use and reflections on these objects and interactions. Our data analysis focuses in particular on the participants' experiences of touching and being in touch with their bodies, including how touch is achieved, and the aesthetics of touching the body. We show the importance of touch in

\footnotetext{
${ }^{1}$ We use the expression "people who menstruate" when referring to people who experience menstrual cycles. This is to emphasize that this group is not homogeneous, that menstruation is not tied to gender, and that some people do not menstruate while using hormonal contraceptives or due to menopause, stress, disease or after a hysterectomy.

${ }^{2}$ Trigger warning: this paper contains images that might be uncomfortable to people who are triggered by blood in general.
} 
helping participants to better understand their changing bodies. We find that by touching the body participants were able to construct new knowledge, reflect on their health, and further develop compassion and appreciation for their body as it changes. Based on the analysis, we argue that menstrual interaction design and technologies must go beyond self-tracking to accommodate and encourage touching and being in touch.

\section{MENSTRUATION IN INTERACTION DESIGN AND HCI}

The menstrual cycle, which spans from the first day of menstruation until the day before the next one, is a major indicator of health and well-being [23, 4]. The menstrual cycle affects the body in drastic ways, including differences in mental health, body performance [73], skin, hair, taste and sight [34]. The accounts of people who menstruate are often ridiculed, dismissed or trivialized $[22,62]$, leading to social and internalized stigma [43] with consequences impacting self-esteem, body image, sexual health, and self-objectification [64]. Often people who menstruate feel social pressure to conceal these experiences, and look for ways to do so [58].

In recent years, menstruation has received increased public attention [72] and political advocacy to open conversations, end stigma and ensure accessible, safe menstrual products for everyone $[61,63]$. Simultaneously, a number of new technologies, products, and services have been designed to offer better menstrual health experiences, e.g., the menstrual cycle tracking app Clue [17], and the hormone-free birth control app Natural Cycles [18]. As digital products for menstruation have increased in popularity, so too has research in $\mathrm{HCI}$ on menstrual hygiene products [51, 54], existing self-tracking technologies [21] and future design proposals [26, 67].

However, the increased attention to menstrual experiences also comes with certain tensions. It is common for the design of menstrual technologies and FemTech products and services to frame menstruation as something in need of fixing, a wrong in menstruating bodies which might be remedied or controlled through technology $[15,36,66]$. The research literature points out that menstrual tracking applications build on assumptions in their designs which are normative, and which cast aside the pluralism of bodies and menstrual experiences [21,36]; in addition, "conforming to societal norms of fitness, productivity, happiness, and appearance is framed as empowering" [26]. Digital fertility tracking methods are also often restricted to binary outputs, and designed for clinical and individual interactions, disregarding the domestic and social layers of women's health [38]. To address the pluralism of bodies and menstrual experiences, as argued by $[35,68]$ it is crucial to move from only addressing the confined space of menstruation to more holistic perspectives on the menstrual cycle. Similarly, as we will argue, we need to carefully consider the role that technologies play in the production of knowledge on the menstrual cycle, and the responsibility or agency people who menstruate have in creating situated knowledge on their own, unique cycles. We address this challenge by exploring what it might be like to design within close relation to the menstruating body, taking into account the knowledge created through the substances and material changes occurring throughout the menstrual cycle.

\section{DESIGNING FOR INTIMATE BODILY KNOWLEDGE}

Research on women's health in HCI has explored experiences of motherhood [6], breastfeeding [5, 19, 39], menopause [11, $37,47,70]$, pelvic fitness [3], menstruation [10, 15, 25, 27, 67], and abortion [52]. A key element of this work concerns the production of situated and embodied knowledge [2], which is a crucial factor towards advancing women's health [1].

In researching intimate care in HCI, Almeida et al. have argued that the majority of technologies and experiences designed for women's health are focused around the body rather than directly engaging with it [2]. They argue that the avoidance of the female body is connected to historical stigma and taboos, partly because intimate care "involves parts of the body that are hidden or involved in sexual functioning" [2]. Along the same lines, the feminist HCI framework [12] highlights pluralism, advocacy, participation and embodiment as important values in interaction design and in the production of knowledge. Labella, an augmented system supporting intimate bodily knowledge and pelvic fitness, is one example of designing for embodiment as a form of knowledge construction [3]. This mobile application encourages its user to look at a representation of one's vagina on the mobile screen and ambiguously asks the user to explore intimate anatomy through touching the screen. Future Flora [69] similarly promotes embodied learning, this time through the design of a kit to treat and prevent vaginal infections by harvesting healthy bacteria and wearing these probiotics in one's underwear.

Existing menstrual technologies provide a closer inspection of the body through data-driven approaches that can enable people who menstruate to develop new understandings of their body [21]. Yet, we encounter few instances of menstrual technologies that encourage an embodied understanding of the menstruating body and its fluids. Moreover, commercially available smart menstrual products propose interactions which seem to avoid touch altogether. Looncup [49] and my.Flow [55] are both internet-connected menstrual management systems that sync to an app, notifying the user when their cup or tampon is full, avoiding leakage and optimizing for as few changes a day as possible. The interaction and learning then take place through the phone screen; the actual touching of the body and its fluids reduced to the minimum.

\section{Touching as a Way of Knowing}

In HCI, touch technologies often refer to touch-based interactions with screens or digital material along with other forms of haptic technologies. Here, we draw instead from a perspective on touch described in feminist technoscience theories [7, 32, 60] which approach touch as the encounters between entities, specifically focusing on the material, sensorial and affective experience of touch.

Karen Barad [7] and Maria Puig de la Bellacasa [60] use the literal and conceptual meaning of touch to theorize feminist knowledge production and to blur the boundaries between subject and object. Touching as a concept for feminist knowledge production is a response to Donna Haraway's critique of the "Godtrick"; a detached and disembodied vision from nowhere as the dominant way of producing scientific knowledge [32]. In menstrual tracking technologies, self-knowledge is created 
through algorithmic processes of the body [21], which merely encourages one to observe the menstruating body through data on the screen: a disembodied vision from nowhere. Instead of producing knowledge by observing the world through vision, Puig de la Bellacasa proposes touching as a material and affective methodology. In contrast, menstrual technologies are designed within a world where societal stigma influences people who menstruate to conceal and avoid their menstruating body-as expressed in recommendations for menstrual apps to "be discreet by default or provide a neutral non-obvious interface option" [21] — thus menstrual technologies are avoiding the intimacy, care, and knowledge implied in touch as far as possible. This is even the case when intimacy through touch might improve the technologies' reliability (e.g., combining basal body temperature with cervical mucus observations [59, 40]). So, we might speculate: What can be known through touching the menstruating body?

As touching produces knowledge through material relations, the act of touching troubles distances between subjects and objects. As Puig de la Bellacasa poetically puts it: "to touch is to be touched" [60]. In the act of touching the menstruating body, the menstruating body is also touching the one who is touching. However, in the menstruating body, subject-object relations are imbued with tension. Menstrual blood, for example, has been characterized as abject: something that is neither $m e$ nor recognizable as a thing [45]. Touching the menstruating body, thus, challenges ideas about where the body starts, where it ends, and how it affects us. Might we consider designing beyond the boundaries between the body and its fluids, and design for what is in between? In [33], Haraway curiously asks: "whom and what do I touch when I touch my dog?" In our work on touching the menstruating body, we might, together with Haraway, ask: Whom and what do I touch when I touch my menstrual blood, saliva, and cervical mucus? Barad continues this speculation by arguing that "[a]ll touching entails the infinite alterity, so that touching the other is touching all others, including the "self", and touching the "self" entails touching the strangers within" [7]. Following this argument, touching entails the reciprocal act of being touched, opening up opportunities for reflecting on one's "self" and potentially for creating new knowledge or meaning of this "self".

Drawing on these theories, we ask: How could knowledgeand world-making processes be created through touching the menstruating body? Through our design work and data analysis, we contribute to previous design and research on menstrual technologies by specifically attending to touching as a way of intimately knowing the menstruating body.

\section{CURIOUS CYCLES}

Curious Cycles is a collection of objects designed to be interacted with over the period of a month, the approximate length of a menstrual cycle. They are designed to be used in the home, with the intention of allowing participants to reflect on their cycle as a whole, attending daily to any changes, as well as providing a choice to engage with these questions individually or with cohabitants, partners, or others. We took inspiration from Gaver et. al's cultural probes [28], since Curious Cycles are intended to be evocative objects and activities that play with ambiguity and unexpectedness. We view Curious Cycles as also sharing some of the intentions of Wallace et al.'s design probes, since they are intended to act as "tools for design and understanding, including the understanding and self-knowledge of the individuals themselves" [71]. With Curious Cycles we hoped to trigger particular kinds of experiences for participants, which we could then discuss with them. Through these experiences and conversations, we intended to probe on possibilities for future menstrual cycle technologies.

In the following section, we outline the outcome of designing Curious Cycles, which followed a Research through Design (RtD) approach [29, 44]. We provide a careful and detailed description and analysis of Curious Cycles since these artifacts are central to our knowledge contribution, and may be generative for other interaction design and HCI researchers exploring similar spaces. The design work was initiated by first-person experimentation [41] and traces of autobiographical exploration [57] by our team, internal workshops, and knowledge exchanges with a medical professor specialized in gynecological endocrinology and a fertility awareness expert. The project took place in Stockholm, Sweden, and our research team is composed of women (ages 26-37) from Europe, North and South America. The Western European context of the research, our cultural backgrounds, and our own diverse experiences of menstruation have shaped the questions we ask throughout this work, influenced by our own curiosity and predisposition to being in touch with the menstruating body.

\section{The Curious Cycles Kit}

The kit consists of a physical and a digital part: a tote bag holding physical objects, and an individual Instagram account. The tote bag includes tangible objects (see Fig. 1), an A2 poster, five envelopes with drawing or writing prompts and a zine with evocative imagery and text. The Curious Cycles objects were designed from the beginning with the intention of being deployed and gifted to participants.

\section{Following the Poster Calendar}

We designed an A2 size poster (see Fig. 1a and Fig. 2, left) as a visual reminder and trigger for reflection, as well as a way to guide participants through Curious Cycles. Similar to an advent calendar, the poster has laser-cut flaps with messages such as "Open before you think you're ovulating" or "Open on the first day of your period", revealing printed prompts underneath. Although the average length of a menstrual cycle is 28 days, this is only an average, and variations from cycle to cycle are normal and healthy [24]. Therefore, on the poster, the phases of the menstrual cycle are represented as wavy and undefined clusters, in contrast to a discrete or linear calendarbased representation, which might set expectations on when the menstrual cycle's phases occur. The size and format of the poster suggest that it may be hung on a vertical surface and displayed in the home. We anticipated that participants would, therefore, think about whether to hang the poster, and where it should be hung (in public, or in private, if at all).

\section{Collecting Menstrual Blood}

This part of the kit consists of a common household item, a transparent glass container with a lid, and a more medical or scientific-like object, an eyedropper/pipette that can be 


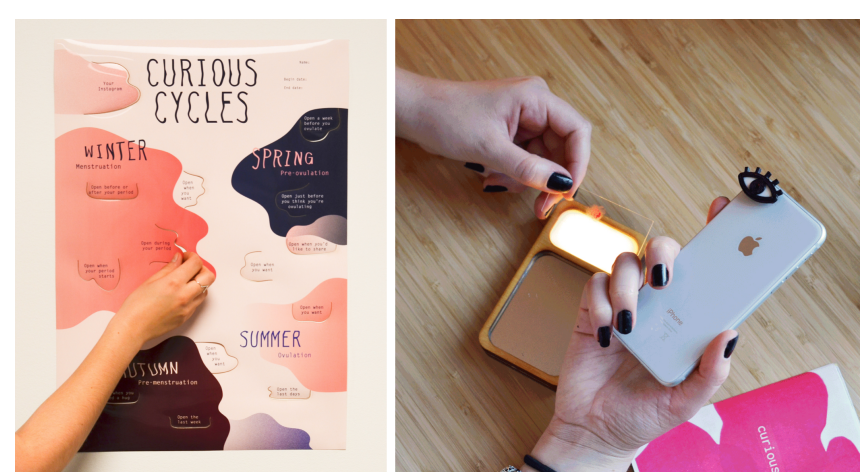

Figure 2. Left: Opening a poster flap. Right: The curious eye microscope attached to a smartphone, to observe a sample of menstrual blood dried on a glass slide, with the help of a backlight from the reflection.
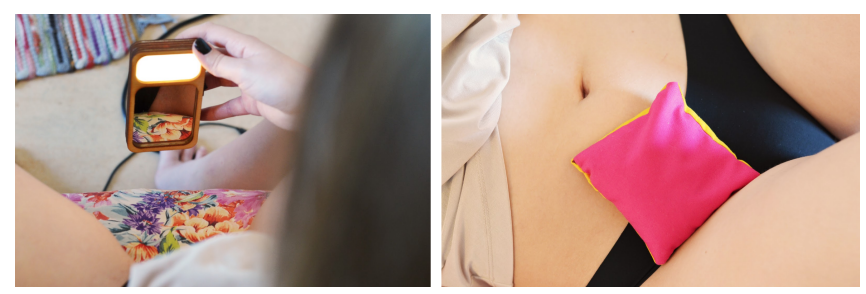

Figure 3. Left: observing the vulva with the reflection mirror and lamp. Right: Feeling the heat pad on the area of the uterus/ovaries.

used to transfer the blood to the provided glass slides for observation (Fig. 1c). The instructions encourage to "collect a bit of your menstrual blood during your period", stating that the method might differ depending on the hygiene product used. They also specify the contents of menstrual blood and clarify that it is harmless unless the person who menstruates carries blood-borne illnesses. Therefore, this design does not introduce any new risks other than the ones already present during menstruation. This experience is purposely messy and low-tech, as the act of retrieving, touching, and observing menstrual blood might be an unfamiliar act in itself.

\section{Observing under a Microscope}

This experiment-like exploration makes use of an object called the curious eye, a small microscope (140X augmentation) attached to the rear camera of a smartphone. The microscope consists of a 3D-printed case shaped like an eye with a small glass sphere embedded into it, acting as a lens (see Fig. $1 \mathrm{~b}$ and Fig. 2, right). The instructions ask the participant to observe three bodily fluids which are relevant menstrual cycle markers: menstrual blood, cervical mucus, and saliva. During ovulation, if sampled and allowed to dry on glass slides, cervical mucus and saliva will form fern-like patterns observable under a microscope [31, 38, 42]. The instructions prompt users to observe the changes in these fluids with the curious eye, as well as to observe changes in the texture of cervical mucus by stretching it between their fingers, as this is also an indicator of ovulation [13]. The poster prompts the repetition of these experiments in different stages of the cycle.

\section{Observing the Vulva}

This experience centers around a handheld mirror with an LED lamp that can be used as a backlight for observing microscope samples (see Fig. 1e and Fig. 3, left). The instructions ask users to use the mirror to look at themselves between their legs, observing the outer anatomy of their vulva and briefly writing about their experience. We expected that by observing their reflection from uncommon and interesting angles, participants might reflect on what values they attribute to their bodies, and spur a sense of appreciation.

\section{Exploring Heat}

Building on work where explorations with heat have helped heighten awareness of different parts of the body [65, 74], the object central to this experience is a small fabric pad filled with rice and lavender (see Fig. 1f and Fig. 3, right). The pad retains heat when warmed up in a microwave or oven, emitting a pleasant smell, and provides an interesting sensation of weight. The instructions encourage moving the pad around the body and noticing any sensations. After these explorations, we suggest sketching or annotating a body map, which is a paper with a blank silhouette of a body on it. Through this experience, we wanted to acknowledge that the menstrual cycle is often responsible for pain, discomfort and emotional variations, and that when designing for menstrual cycles it is important to not overlook or try to conceal these sensations.

\section{Reflecting on paper}

In a similar attempt to foster acknowledgment and acceptance of the plurality of menstrual experiences, we included a drawing activity asking participants to draw their metaphorical menstrual "monster" or "creature". Monstrous, deviating from the norm, noncompliant or irrational: in this exercise, we intend to reclaim these negative values often associated with people who menstruate, questioning the default way of being as non-menstrual, static and unchanging. Other reflective activities, delivered in envelopes (see Fig. 1d) include annotating the experiences of one's cycle on the outline of a circle, and brief reflections on menstrual tracking apps.

\section{Taking and Posting Pictures}

One of the poster's flaps includes login credentials for an individual, private Instagram account that participants can use as a diary or blog, or to appropriate how they wish. Several flaps ask to take pictures of specific objects and places, such as menstrual hygiene products, or where the poster is hung. In addition, the instructions also invite participants to post pictures on the Instagram account as they conduct the experiences.

\section{DEPLOYING CURIOUS CYCLES}

A call to participate in our study was posted online and distributed across the first author's extended social circles. The call targeted anyone living in Stockholm, Sweden, who menstruated and who was not currently using hormonal contraceptives. We were interested in the experiences of people not using hormonal contraception as they may encounter more noticeable changes in their bodies throughout the menstrual cycle. We specified that volunteers should be willing to look at and touch their menstrual blood, cervical mucus, and saliva, and to make use of an Instagram account on their smartphone. 
We reached out personally to both binary and non-binary people; among these, one non-binary candidate decided to not take part in the study and another did not fit the requirement about hormonal contraception. The call received around twenty interested people. Among other criteria, such as living situation and cultural background, we selected five participants with the widest age range in order to include a rich variety of experiences.

Five women, aged 22 to 37, participated in the study. They were from one or several countries, including Canada, Germany, Moldova, Spain, Sweden, and Switzerland. Two participants who were recruited simultaneously knew each other prior to the study, and one participant was a recent mother. We crafted five sets of Curious Cycles and delivered them in individual meetings. In each meeting, the first author explained the objects, indicated the approximate amount of time needed for each activity, clarified that there were no right, wrong or expected responses, and answered participants' questions. We informed participants that it was up to them to change the privacy settings and (un)follow other Instagram accounts. Participants were also told they could keep their kit. We obtained participants' written consent after specifying the motivation for the study and its duration, the activities to be carried out, any expected risks, the type of data collected (including the voice recording of the interview, notes and drawings from the paper-based activities and photographs, captions and comments from the Instagram account) and its confidential nature. Participants all agreed for this data to be used anonymously in subsequent publications. Participants were also advised they could withdraw their participation at any moment.

Our study began as soon as participants took their kit of $\mathrm{Cu}-$ rious Cycles home, starting at different stages of each participant's menstrual cycle. Because of this, we asked them to inform us when they considered that a full cycle had been completed. We set up individual semi-structured interviews with the first author. These conversations lasted from 40 minutes to 1 hour and 20 minutes and were conducted in English or in the language preferred by the participant and also spoken by the first author. The interviews took place in spaces suggested by the participants, four in public settings and one in the participant's home. The first author recorded the audio and took notes during the interviews, as well as pictures of the paper-based reflective activities. We also collected screenshots of the Instagram posts and comments. In preparation for the analysis, the first author translated the non-English content and anonymized all the data.

\section{LIVING WITH CURIOUS CYCLES}

The data collected through the deployment of Curious Cycles was analyzed using thematic analysis [14]. Initially, the first author familiarised herself with the data (interviews, Instagram posts and writing and drawing exercises) and coded it. This exploratory inductive thematic analysis across the full dataset resulted in several themes that richly articulated participants' reflections on their menstruating bodies. All authors then reviewed the themes and associated data. Discussions amongst all authors identified codes and themes relating to "touch" as being of particular interest, since we considered it to offer generative opportunities to the interaction design community. To further develop our understanding of "touch" within the data, we conducted a second deductive thematic analysis over the full dataset. In what follows we show how participants described their experiences of touching their bodies, the ways in which they touched, and how touching helped to develop greater knowledge and care for their ever-changing bodies. Participant pseudonyms are used throughout.

\section{Touching and Looking at the Menstruating Body}

In this theme we present participants' experiences of touching their body and their fluids, making use of the Curious Cycles kit, along with the reasons why touching might be interesting to them. From the data, we have identified interactions of touch, but also of looking: looking at the body attentively and in close proximity, possibly as an invitation to further touch [60]. We see a difference between superficially seeing the body, or a representation of it, and actually looking, enabling reflection. This deeper mode of looking is closely linked to the act of touching, as we further develop throughout our analysis.

\section{Ways of Touching}

On the first days of their menstruation, the poster prompted participants to collect samples of their menstrual blood. They were not instructed on how to achieve this, but the Curious Cycles kit contained a pipette and a small, lidded jar. Participants Emma and Julia both described the task as familiar and straightforward: they would empty the contents of the menstrual cup into the jar, or transfer a sample from the cup to a microscope slide, testing both with the pipette and with their finger. Participants explained that they were comfortable with touching because of their use of the cup (Emma, Julia) or reusable sanitary pads (Maria), but that they might have not been so comfortable before switching to these methods:

"I guess before I ever used the cup I was less familiar with the different consistencies especially, but also with the color [...]. I guess I would have been a little less comfortable or aware if I hadn't used the cup." - Emma

"It would have been interesting for me to do that [touch her blood], when I was uncomfortable (laughs), because I don't know if I would have done it."- Maria

Maria explained that reusable pads were the best choice of menstrual hygiene products for her, although it resulted in "so much trouble" to use them every month. She explained that, for the study, she could not obtain blood from her reusable pads, so she attempted a different way:

"I couldn't get blood from the pad, so I had to "tck tck" [gestures putting a finger in and out the vagina] and it was interesting because it was at the end of the period but there was a lot of blood still, it was all bloody." Maria

Laura also resorted to obtaining the blood with her fingers when the use of tampons and period-absorbent underwear failed for the task. Hannah expressed frustration when she was not able to collect blood every day as she would have liked to, and how she switched from trying to squeeze it from tampons or swabbing a pad with her finger, to finally using the pipette: 


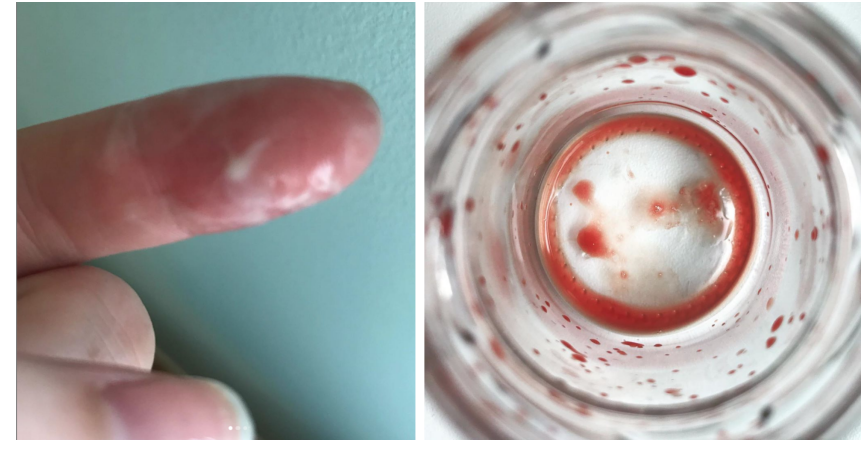

Figure 4. Hannah's pictures. Left: Touching cervical mucus. Right: Collecting samples of menstrual blood.

"I really liked it, but it was so frustrating [...] because I used the pipette to take blood, like... at the spot, like there, yeah, because I just couldn't manage to get it anywhere else." - Hannah

When using the heat pad, participants placed it on their skin and felt its weight, recalling the feeling of how the heat "spread out, like a circle" (Hannah), and made them feel so comfortable they "didn't want to go to work" (Laura). These interactions can also be considered a way of touching, taking place through the heat pad, as when Julia spoke about touching the pad on her chest: "I felt my heart rate better [...] I enjoyed it most where the blood veins were close to the surface."

Participants approached the storage of the tools, their use, and the resulting collected materials in different ways. Some were stored away in the tote bag afterward (Emma), some remained in the shared bathroom (Laura), on the washing machine (Emma), or were moved to the bedroom:

"When it was cervical mucus or taking my blood it was in the bathroom, but then I would usually put it on the plates and take it back to my room because I have more space, [...] I can sit on the floor [...] and also the light is better." - Julia

Some interactions took place in a private bathroom with no windows (Maria), or on a tray that could be easily moved around and hidden from guests (Hannah) (Fig. 6, right).

\section{Reasons to Touch}

One reason to touch was to understand the biological processes taking place during the cycle and the overall health status:

"I usually pay attention to the color of the blood. That tells me if I'm healthy or not, and if I have, like, low iron levels, which I really noticed this time, because the first day was kind of transparent, it was kind of pinkish, like diluted [...].” - Maria

Mucus and saliva were exciting newfound markers during participants' cycles, signaling ovulation, as Emma explained: "I had no idea about this [ferning in saliva] and I thought it was SUPER interesting to do it, I really enjoyed it." Participants identified their approximate ovulation day by touching and stretching the mucus textures between their fingers (Hannah,
Laura and Maria) and by successfully observing ferning patterns in saliva (Julia and Emma). None of the participants were familiar with the meanings of the changes in texture and consistency of their cervical mucus, and the instruction to touch facilitated that knowledge:

"I notice the mucus textures all the time, but I didn't associate it with this, I never connected it. That was very informative for me, I really liked that part."- Maria

After touching her cervical mucus, Hannah recalled that "it would be interesting to take a fertility test now, to confirm the mucus texture", noting how it might be important to triangulate her experimentation with another known test to better understand the body's discharge. When observing her blood sample, Julia questioned what she saw, "like, what is the white stuff? [...] you can't really determine on what level you are", which also highlights how touching and looking might lead to further questions about what exactly it is that one is touching. However, touching in order to understand the body's processes and health status is not the only reason to touch. Maria also expressed how understanding the cervical mucus textures did not need to be just a means to pinpoint fertility: "I need to know because it's my body, that's why I need to know" and to understand "what's going on" (Hannah).

Looking at the vulva supported by the mirror made participants think about the reasons why they were looking, which, in this case, was not for health concerns. Moreover, participants reflected on why they had not been looking before, or even how a sense of permission or instruction was necessary:

"It felt so interesting to be forced, in a way, to make myself aware of things. Some of it was like, why don't I do that normally?" - Hannah

"I had never done it before [...] I thought, it's obviously easy, we can probably find mirrors around our home." Laura

Participants recalled spending longer than expected looking at the vulva (Maria) or even feeling the need to clip the hairs surrounding it in order to get a better view, as Laura explained: "There are areas you can't see from any perspective, so you don't really know what they're like. Sometimes it's there, under the hairs, and it's there, but it's not there (laughs)." Therefore the motivation to look, which, in this case, led to touch, was triggered by direct instruction, or because "time goes by, and you think about doing it, but you don't until you have to" (Laura). Facilitated by the mirror, looking at and touching the vulva turned from a learning-driven action into a "this is what it looks like? really?" (Maria) action.

\section{Being in Touch with the Menstruating Body}

We describe how participants were touched by their interactions with their menstrual cycles, including if and how the participants changed their appreciation for their menstruating body, becoming more aware, "in tune" or "in touch" with it.

Emma and Julia both managed to take pictures of ferning patterns in their saliva (see Fig. 5, right). Emma reflected on the pleasing experience of discovering these patterns: 


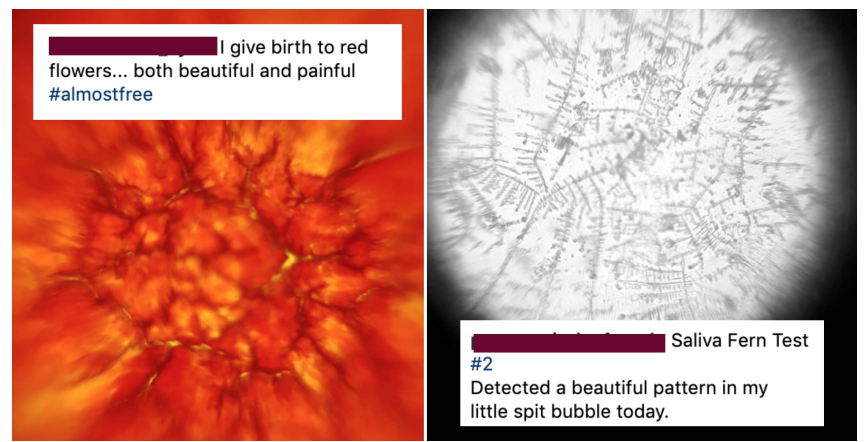

Figure 5. Left: Instagram post and caption from Maria. Sample of dried menstrual blood using the curious eye microscope. Right: Saliva observation and caption from Julia using the microscope, indicating fertility.

"I did it every day until I saw the ferning patterns, I needed to see them. [...] I really enjoyed it because I had no idea that the patterns would change [...] and I thought it was actually really aesthetically beautiful as well [...] and seeing how aesthetically pleasing it was, it also kind of gave me this new appreciation for it." - Emma

Touching the fluids, combined with looking, photographing, curating, and posting pictures of them triggered reflections on the aesthetics of these fluids, attributing values to something that is normally discarded and considered waste. Maria captioned a picture of her blood under the microscope as "red flowers, both beautiful and painful", and Julia described it as both "strange and fascinating". Hannah's frustration around not being able to collect every day drove her to be more attentive to the encounters with her blood. This made her feel like her menstrual blood was suddenly precious and valuable:

"How I managed to take this blood sample [points to picture] was like day three or something, I had it on my paper, it's so funny, because it got so precious, to collect stuff (laughs) [...] and I ran to the bedroom and put it on a clean slate so I could have it there, and then had it dry, because I was like oh! this is a good thing!" - Hannah

When posting a picture of cervical mucus on her finger (see Fig. 4, left), Hannah remarked: "Why do I feel so weird about this? [...] and who wants to see this?", questioning if her social circles would accept the picture if it had been on her personal account. This also spurred reflections on the values she, and the world, associate with these fluids, admitting that "it also felt a bit liberating, and it looked very artistic", indicating a certain appreciation for the image.

When using the mirror to look at their vulva, participants reflected on their expectations and the unfamiliar experience, anticipating that appreciation takes time and practice:

"You don't see it all the time, maybe if I saw it more I'd feel like, oh, maybe it's not that bad." - Maria

"I felt like the experience of using the mirror helped me to sort of break down some barriers of [...] self-stigma or internalized stigma. [...] We're constantly told our bodies are gross, unhygienic, and ugly and these things, and this was something I think I really internalized. So taking time to just look at yourself and say, yeah, this is a normal way to look, it helps to be like, yeah, this is me and that's cool and that's fine." - Emma

The experiments inspired observations shed of presumptions, which, with time, could foster self-acceptance and admiration of the menstruating body. Laura wrote that she would continue exploring with the mirror, and considered the object to be "a gift", Hannah acknowledged the power of her vulva after closely observing it, and Emma wrote about her feeling of "being in touch" with herself after looking:

“I don't think they're pretty [vaginas], really, but it was fascinating, that I made a human out of it [...] It's super powerful." - Hannah

"It's surprising how novel it is to be intimate with yourself. To observe yourself when you're vulnerable without judgment, and perhaps even with admiration. Women are taught to hate their bodies - that we're gross. The small act of looking at one's own vulva without shame or judgment defies this. It helps me defy it." - Emma

The materials used in the designs enabled participants to be in touch with their values towards their menstruating body. All participants rejected cute, childish and girly aesthetic values in association with their menstruation. Maria, Hannah, and Julia criticized their current menstrual app for having "immature" and "innocent" visuals. Participants also agreed that the hard but warm feeling of the wood of the reflection was welcoming to the intimate area. Emma reflected on her associations between materials and a sense of being in control of her body:

"I'm picturing that pink fake fur type stuff, it would be super cliche and I think it would make me feel kind of stupid. [...] In the situation where you're trying to look at yourselffor non-sexual reasons, then if you use some sort of material that then makes you feel sexualized again, it's almost like the sexualization is out of your control [...] I think we already feel that way a lot. [...] I guess I never realized it before this conversation, but, the different materials can definitely make you feel like you have more of that control or less of that control." - Emma

The notion of "being in control" was used among participants to express the ownership of their sensitive information, regarding privacy concerns in their menstrual tracking apps, but also, as Emma uses the term here, to have a decision over her values, to not be forced to stigmatize or sexualize her own body.

As the study concluded, participants were asked to draw their cycle as a circle, in an effort to recall the subtle noticing that the objects had facilitated throughout the month. Hannah described a change in how she perceived her cycle:

"This has been an eye-opener for me, really looking at the cycle as a circle, as a whole, and not like, this is one week every month." - Hannah

Julia asked herself what her feelings towards her menstrual cycle were, finding a metaphor to explain the balance between her negative and positive menstrual experiences: 


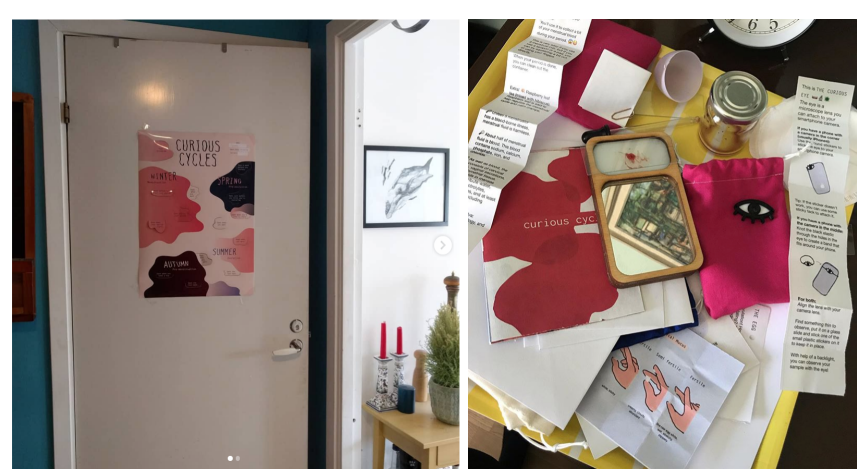

Figure 6. Left: Emma's poster in her shared apartment. Right: Hannah's kit on a tray that could easily be moved around the home.

\begin{abstract}
"My feelings towards my menstruation could be compared to those I have towards bees. I don't enjoy being around them but I appreciate the services they do. And every time they come back I am glad that the world I know still exists as in not being pregnant or still having fruit on the trees." - Julia
\end{abstract}

By seeing menstrual blood, mucus and saliva as precious and valuable, rather than waste, and through the power of looking and touching over time, participants strive for a sense of aesthetic appreciation, admiration, of being "in touch" with the changing body, along with being "in control" of the values associated to this body.

\section{Nurturing and Fueling Appreciation}

While the sociocultural contexts of menstruation have been discussed previously [20,43,45], our analysis draws attention to how social factors came to play in participants' experiences of touching. In the first week of the study, four out of five participants unexpectedly followed each others' Instagram accounts. They began to acknowledge and interact with each other's content, give each other tips on how to use the microscope, and collectively review and recommend menstrual tracking apps. The social support was important to manage difficulties with the tools provided in Curious Cycles and the materials (capturing the ferning, in particular, is tricky), and the "sense of community" (Julia) was highlighted. Through an exchange of comments, Emma explained to Hannah how she positioned her smartphone and the slide in the air to get a better shot of her saliva, to which Hannah replied: "Will give it a try! Thanks :)", and Emma encouraged: "Hopefully it goes well for you! I'll keep an eye out for your results."

Aside from advice on using the tools, Instagram was also used to nurture appreciation of menstrual experiences. Hannah's picture depicting a bloodstain on her underwear helped Emma feel more comfortable with her own experiences:

"The first time I posted a picture of my blood I felt weird, but then I thought, oh why am I feeling this, it's just blood.

[...] One girl posted bloody underwear and I was like what! that's so cool!" - Emma

All participants hung the poster (see Emma's poster in Fig. 6 , left), which spurred conversations on how the designed objects lived in their homes, sometimes welcomed by cohabitants (Emma, Julia, Hannah) but also sometimes not—causing frictions to surface when crossing into shared spaces:

"I'm offended about this from my partner. He made faces at me [when I was doing the experiments]. He said, "I see it [the blood]". And I was like "yeah I know you see it". And he said, "yeah but you know it bothers me a bit" [...] If you get dizzy when you see blood... but this isn't the case. I asked him to make an effort." - Laura

In response to her partner's rejection of the touching and looking experiences, Laura further fueled the appreciation of her body by asking him to be part of the experiments: "I asked or sort of forced him to help me use the microscope"; to test the boundaries of their shared space: "I even provoked him a bit by leaving the blood out"; and to discover to what extent her social media circles would also accept these experiences: "I posted a picture of the blood on Facebook asking "what is it?" [...] But I was disappointed, nobody said anything."

Finally, through being in touch with their menstruating body, participants reflected on what it would take to nurture this appreciation for the menstruating body into others, into society, overcoming taboos and normative expectations:

\begin{abstract}
"Before [when I was younger], I would judge other women when they would stay home, like, I feel pain but I still come! But I don't know! I don't know how much pain she has. Even other women expect you to carry on as normal [...] it's not fair that I have to do the same things even if I can't." - Maria

"It's not just about menstruation, it's about so much more. It is very connected to being a functioning person, which is very weird in a way, that you only have this one purpose in society, to make a baby or reproduce in some way, and it's an expectation [...]." - Hannah
\end{abstract}

\section{DISCUSSION}

In designing Curious Cycles, we intended to invite people who menstruate to be in close contact with their bodies: giving technology the role of a mediator that allows people to produce their own knowledge, rather than a layer through which people gain knowledge about their menstruating body. As opposed to dominant menstrual cycle technologies today that mainly obtain data about the body through sensors or self-tracking, in Curious Cycles, self-touch is a crucial part of exploring and better understanding one's body. In the following sections, we discuss how through Curious Cycles, participants became in touch with their menstruating body, slowly starting to build a sense of appreciation for it, including its fluids. We consider how intimate touch can be invited and mediated by technology through designing with curiosity in mind and we open a conversation with our community about what it might mean to design with and for bodily fluids.

\section{Inviting and Mediating Touch}

Technologies of intimate care such as Labella [3] have shown how situated embodied perception, where interactions happen beyond the screen, is important to promote learning of hidden parts of the body. In Curious Cycles, we ask participants 
to go a step further, explicitly inviting them to look at and touch their own body, instead of a universal representation on a mobile phone. In this case, the learning value is less focused on an anatomical or medicalized reference of the vagina or a calendar referencing the menstrual cycle, but on a close and caring observation of the self. To look closely, or as Puig de la Bellacasa phrases it: to look with "fingery eyes" [60], enables a deeper mode of looking, a way of seeing-touching what we encounter in the world, and in this case, when we encounter the menstruating body. By looking through the microscope and at the blurry and intimate images it produces, taken at "an almost touching closeness" [60], participants observe their body with what Marks describes as "a small caressing gaze" [50]. Looking intently and closely can equate to touch, and can facilitate a sense of being in touch with the body. Critically, our analysis suggests that what participants encountered when touching developed a sense of caring appreciation for the menstruating body. Rather than being gross and impure, they found their bodies and their bodily fluids "messy" and "dirty", but "beautiful", "pleasing", or even "beautiful and painful", or "strange and fascinating". This appreciation for the menstruating body also seemed to extend from their own to other menstruating bodies, as well as to fuel a desire to change perceptions about them. Touching the self, the act of self-touch, as we have shown through our analysis, is "touching the strangers within" [7], a way to learn and understand the self, to be "in touch" with the self, and all menstruating others.

However, to touch is not necessarily easy. In fact, much like Labella [3], participants emphasized the need to be invited (or given permission) to look and touch. This is surprising since participants already had a certain closeness to their body, as evidenced by their use of non-mainstream products such as menstrual cups. The societal norms that raise people who menstruate to express discomfort with their bodies, and feel disgust when coming into contact with the messiness of the menstruating body are strong and deeply held by many.

We have found that if you ask people to look, or to touch, they will curiously follow. Menstrual technologies thus need to provide an invitation to touch the body and its fluids. And, precisely because the act of touching is unfamiliar and strange, the design of this invitation and experience might involve overcoming several initial boundaries, such as social taboos, disgust and stigmatization of the fluids, or shame to look at and touch intimate areas of the body. In Labella [3], humor and awkwardness were interaction design devices used to invite the person to look. In Curious Cycles we designed rather to provoke a sense of curiosity. Playing with ambiguity [30] and the unfamiliarity of the interactions afforded by the tools, combined with colorful, playful, soft, and welcoming materials, allowed participants to approach the objects shed of preconceived values, such as sexualization or gendering of these parts of their body.

\section{Designing with and for Bodily Fluids}

Our lasting sense from the data is that there is power in touching the body for oneself - both in terms of the emancipation and appreciation that can be achieved by breaking this taboo, but also in terms of the knowledge about the self which is possible to develop as a result of this touching. Here such knowledge extends from general health, supporting or reducing the chance of becoming pregnant, and noticing symptoms of diseases or disorders. It would be tempting for menstrual technologies to sanitize this touching, as commercial products such as Looncup [49] and my.Flow [55] already work towards - measuring and analyzing the menstrual fluids for their users. However, based on our data, this would sidestep the benefits of touching. Instead, we argue that technology's place here is to invite, and to potentially mediate this touch, not to be the "gatekeeper" to knowledge about the body.

We can draw from existing exemplars in recent literature to imagine what such interactions might look like. For example, while designed as a provocation around human-fungi relationships, the Hand-Substrate Interface [48] embodies some of the qualities we envisage in future menstrual technologies that promote touch of the body. Its design intends to promote an "art of noticing" that allows the wearer, through mediated touch, to learn more about the substrates within which mushrooms are growing, developing an understanding of how different levels of moisture support fungal growth. It is not a great leap to imagine similar technologies that allow mediated touch of the menstruating body, enabling the wearer to piece together the viscosity, volume, and color of bodily discharge in their menstrual cycle. What is promising about such approaches is the potential to generate knowledge about particular environmental conditions (whether in the forest or in the body) that might also become accessible when not wearing such a device.

Designing with and for interactions with bodily fluids and menstrual blood requires careful ethical management to determine how to incorporate design explorations with such materials not only in the homes of participants, but also in other potential research environments. Designing for touching menstrual blood, cervical mucus and saliva of one's own body is not dangerous or toxic, and does not add any risks aside from the ones people who menstruate already encounter with their cycles every month. People are becoming more and more in contact with their blood and mucus when using menstrual hygiene products, in part due to the increase of menstrual cup usage, especially in a European context [53]. In this work, we have gone a step further than day to day encounters and asked participants to notice and pay attention to these fluids that are a normal part of the discharge of their bodies. This opens up questions about treatment, storage, and disposal which must be attended to by both the researchers and the participants. With at least one participant, our study highlighted the stigma that can be associated with menstrual blood and the menstruating body. The participant's partner did not want to see the menstrual blood or be near collected samples. Curious Cycles-in asking her to collect, store and observe her fluids-supported the participant in confronting her partner on this matter, enabling her to directly challenge this stigma. Our designs provided the opportunity to touch and collect, to perceive this discharge as precious, and something which should be looked at and might be considered as beautiful. Vitally, Curious Cycles provided a place within the home for these discharges, rather than 
treating them as something that should be immediately thrown away. Based on our data, we believe that future menstrual technologies should help to directly challenge the stigma and misunderstanding of, in particular, menstrual blood.

Despite these fluids being non-toxic and not dangerous, they are bodily fluids and as such, must be treated with care. Researchers must consider that menstrual blood contains venous blood, which may carry blood-borne infections and diseases, including sexually transmitted ones. Thus, interaction design needs to develop processes and practices which enable us to experiment and design with these materials safely. To achieve this, we should take inspiration from emerging practices such as [46] who examine how to transition an HCI studio into a BSL-1 (biosafety level 1) facility using low-cost tools, to develop DIY bio protocols. Similarly, we can be informed by current DIY approaches to gynecology, such as [16] and seek to design methods and tools that resist institutionalized views of menstruation, allowing the conversations and knowledge production about menstrual cycles to happen also in the home.

\section{An Ecology for Menstrual Experiences}

As seen in previous work [27, 38, 67], menstrual cycles are not isolated and individual experiences, and menstrual technologies increasingly mirror this consideration. For example, menstrual tracking apps like Clue allow for sharing data, recognizing its potential to support social bonding [17]. In line with [56], our data includes positive reflections on existing self-tracking practices, illustrating that touch and self-tracking could coexist and contribute to the generation of bodily knowledge. Our work opens the path for interactions that could include self-tracking, e.g., in explorations of cervical fluid.

In Curious Cycles, the objects and interactions exist in an ecology [12] among other menstrual products, artifacts, and people in shared environments, which directly influences the ways in which participants touch and look. By being physically present and taking up space, the Curious Cycles kit required management and shed light on the existing tensions of sharing or hiding menstrual experiences. At times, participants protected themselves from possible shame or stigma in their homes by hiding the objects and the experimentation, e.g., by choosing to use private, potentially lockable spaces such as a bathroom, or moving objects out of sight when visitors arrived. However, at other times, they made their experiences visible, provoking and testing the limits of their social surroundings. We note similar choices in relation to the sharing (or not) of digital content. The participants in our study improvised a social context to support their learning to touch and to be in touch with their body, by choosing to follow one another on Instagram. As one might expect, they liked each other's images and left comments on their posts, which, in turn, encouraged continued experimentation, posting content they would have not released to their normal social circles, and inspired further rethinking preconceptions about the menstruating body. This combination of physical and digital sheltering and display of content relating to menstrual experiences is not surprising, but serves to highlight how ecologies for menstrual experiences need to be considered in the design of menstrual technologies; that is, how menstrual technologies become part of an ecology of artifacts in a person's home and everyday life, which is also inhabited by other social actors.

We argue that menstrual technologies should accommodate for discreetness [21] and camouflaging, similar to the design of sex toys [8], but also be designed for "showing off" when wanted. They should display material choices and aesthetic qualities that carefully consider what they communicate about the body (e.g., sexualized, medicalized), which are sensitive to cultural context. For example, the participants rejected gendered, pink or infantile aesthetics, while in other contexts, those qualities might be preferred in order to overcome cultural taboos [9]. The bare material qualities suggested by participants, such as wood or concrete, were in line with findings in [21] about users of menstrual tracking apps considering "femininity a more negative design trait."

Finally, menstrual technologies should consider the relationship with the menstruating body as it changes over life. Of particular interest are key reproductive transitions, such as menarche and menopause, where people must adapt to a new body, identity, and social roles, often in a context of taboo and stigma. Our data does not account for the specific experiences of hormonal contraceptive users, young menstruators or people going through menopause, but we are engaging with these populations in dedicated research projects, seeking to incorporate their voices.

\section{CONCLUSION}

In Curious Cycles we highlight the exploration of bodily fluids, opening opportunities for the design of body-centric technologies to include this part of the body. Through an RtD approach, we found ourselves questioning the encounters and cuts between the body and its fluids, raising questions such as: Where does my body end and where does "the other" begin? Designing for the body need not stop at the skin, but consider the inbetweenness; imagining these fluids as an extension of the body, where it is difficult to discretely discern the inside from the out.

In a future envisioned with novel medical and health applications, such as smart menstrual technologies in constant connection and production of a swarming buzz of data, we must not forget the material, sensorial, and affective experiences of menstruating bodies that will be engulfed by these systems and devices. Our work shows that by seeking the active involvement of people who menstruate with their own bodies, designers can build menstrual technologies that care for and appreciate menstruating bodies as they are and as people themselves choose them to be. Through touching and being in touch with the menstruating body we invite people who menstruate to nurture and fuel intimate appreciation and bodily knowledge, opening opportunities for those in the surroundings to also become in touch with these bodies, and, in turn, to reconfigure the societal discourse of menstruating bodies.

\section{ACKNOWLEDGMENTS}

We thank our study participants for sharing their experiences with us, the Soma Design team at KTH, Emmi Parviainen and the MIDDLA lab. This work was partially funded by the Swedish Research Council project 2017-05133. 


\section{REFERENCES}

[1] 2019. UN Women - United Nations Entity for Gender Equality and the Empowerment of Women. (2019). https://www.unwomen.org/en

[2] Teresa Almeida, Rob Comber, and Madeline Balaam. 2016a. HCI and Intimate Care as an Agenda for Change in Women's Health. In Proceedings of the 2016 CHI Conference on Human Factors in Computing Systems CHI '16. ACM Press, Santa Clara, California, USA, 2599-2611. DOI :

http://dx.doi.org/10.1145/2858036.2858187

[3] Teresa Almeida, Rob Comber, Gavin Wood, Dean Saraf, and Madeline Balaam. 2016b. On Looking at the Vagina through Labella. In Proceedings of the 2016 CHI Conference on Human Factors in Computing Systems CHI '16. ACM Press, Santa Clara, California, USA, 1810-1821. DOI :

http://dx.doi.org/10.1145/2858036.2858119

[4] American Academy of Pediatrics, Committee on Adolescence, American College of Obstetricians and Gynecologists, and Committee on Adolescent Health Care. 2006. Menstruation in Girls and Adolescents: Using the Menstrual Cycle as a Vital Sign.

PEDIATRICS 118, 5 (Nov. 2006), 2245-2250. DOI: http://dx.doi.org/10.1542/peds.2006-2481

[5] Madeline Balaam, Rob Comber, Ed Jenkins, Selina Sutton, and Andrew Garbett. 2015. FeedFinder: A Location-Mapping Mobile Application for Breastfeeding Women. In Proceedings of the $33 \mathrm{rd}$ Annual ACM Conference on Human Factors in Computing Systems - CHI '15. ACM Press, Seoul, Republic of Korea, 1709-1718. DOI : http://dx.doi.org/10.1145/2702123.2702328

[6] Madeline Balaam, Judy Robertson, Geraldine Fitzpatrick, Rebecca Say, Gillian Hayes, Melissa Mazmanian, and Belinda Parmar. 2013. Motherhood and HCI. In CHI'13 Extended Abstracts on Human Factors in Computing Systems on - CHI EA '13. ACM Press, Paris, France, 3215. DOI : http://dx.doi.org/10.1145/2468356.2479650

[7] K. Barad. 2012. On Touching-The Inhuman That Therefore I Am. differences 23, 3 (Jan. 2012), 206-223. DOI : http://dx.doi.org/10.1215/10407391-1892943

[8] Jeffrey Bardzell and Shaowen Bardzell. 2011. Pleasure is your birthright: digitally enabled designer sex toys as a case of third-wave HCI. In Proceedings of the 2011 annual conference on Human factors in computing systems - CHI'11. ACM Press, Vancouver, BC, Canada, 257. DOI : http://dx.doi.org/10.1145/1978942.1978979

[9] Jeffrey Bardzell and Shaowen Bardzell. 2018. "My Peaceful Vagina Revolution:” A Theory of a Design: From Usability to Enjoyment. 77-91. DOI : http://dx.doi.org/10.1007/978-3-319-68213-6_6

[10] Jeffrey Bardzell, Shaowen Bardzell, and Lone Koefoed Hansen. 2015. Immodest Proposals: Research
Through Design and Knowledge. In Proceedings of the 33rd Annual ACM Conference on Human Factors in Computing Systems - CHI '15. ACM Press, Seoul, Republic of Korea, 2093-2102. DOI : http://dx.doi.org/10.1145/2702123.2702400

[11] Jeffrey Bardzell, Shaowen Bardzell, Amanda Lazar, and Norman Makoto Su. 2019. (Re-)Framing Menopause Experiences for HCI and Design. In Proceedings of the 2019 CHI Conference on Human Factors in Computing Systems - CHI '19. ACM Press, Glasgow, Scotland Uk, 1-13. DOI : http://dx.doi.org/10.1145/3290605.3300345

[12] Shaowen Bardzell. 2010. Feminist HCI: taking stock and outlining an agenda for design. In Proceedings of the 28th international conference on Human factors in computing systems - CHI'10. ACM Press, Atlanta, Georgia, USA, 1301. DOI :

http://dx.doi.org/10.1145/1753326.1753521

[13] Jamie L. Bigelow, David B. Dunson, Joseph B. Stanford, René Ecochard, Christian Gnoth, and Bernardo Colombo. 2004. Mucus observations in the fertile window: a better predictor of conception than timing of intercourse. Human Reproduction (Oxford, England) 19, 4 (April 2004), 889-892. DOI :

http://dx.doi.org/10.1093/humrep/deh173

[14] Virginia Braun and Victoria Clarke. 2006. Using thematic analysis in psychology. Qualitative Research in Psychology 3, 2 (Jan. 2006), 77-101. D0I :

http://dx.doi.org/10.1191/1478088706qp063oa

[15] Nadia Campo Woytuk, Linette Nilsson, and Mingxing Liu. 2019. Your Period Rules: Design Implications for Period-Positive Technologies. In Extended Abstracts of the 2019 CHI Conference on Human Factors in Computing Systems - CHI EA '19. ACM Press, Glasgow, Scotland Uk, 1-6. DOI :

http://dx.doi.org/10.1145/3290607.3312888

[16] Ewen Chardronnet. 2015. GynePunk, the cyborg witches of DIY gynecology : Makery. (June 2015). http://www.makery.info/en/2015/06/30/gynepunk-lessorcieres-cyborg-de-la-gynecologie-diy/

[17] Clue. 2019. Period and Ovulation Tracker for iPhone and Android. (2019). https://helloclue.com

[18] Natural Cycles. 2019. The First Birth Control App I Hormone-Free Birth Control I Natural Cycles. (2019). https://www.naturalcycles.com/,https: //www.naturalcycles.com/

[19] Catherine D'Ignazio, Alexis Hope, Becky Michelson, Robyn Churchill, and Ethan Zuckerman. 2016. A Feminist HCI Approach to Designing Postpartum Technologies: "When I first saw a breast pump I was wondering if it was a joke". In Proceedings of the 2016 CHI Conference on Human Factors in Computing Systems - CHI '16. ACM Press, Santa Clara, California, USA, 2612-2622. DOI :

http://dx.doi.org/10.1145/2858036.2858460 
[20] Mary Douglas. 2005. Purity and danger: an analysis of concept of pollution and taboo. Routledge, London ; New York. OCLC: ocm50333732.

[21] Daniel A. Epstein, Nicole B. Lee, Jennifer H. Kang, Elena Agapie, Jessica Schroeder, Laura R. Pina, James Fogarty, Julie A. Kientz, and Sean Munson. 2017. Examining Menstrual Tracking to Inform the Design of Personal Informatics Tools. In Proceedings of the 2017 CHI Conference on Human Factors in Computing Systems - CHI '17. ACM Press, Denver, Colorado, USA, 6876-6888. DOI :

http://dx.doi.org/10.1145/3025453.3025635

[22] Breanne Fahs. 2016. Out for blood: essays on menstruation and resistance. State University of New York Press, Albany.

[23] Miranda Farage. 2006. "The Vulva: Anatomy, physiology and pathology" Edts. M.A. Farage and H I Maibach. Informa Publisher-2006.

[24] Richard J. Fehring, Mary Schneider, and Kathleen Raviele. 2006. Variability in the Phases of the Menstrual Cycle. Journal of Obstetric, Gynecologic \& Neonatal Nursing 35, 3 (May 2006), 376-384. DOI : http://dx.doi.org/10.1111/j.1552-6909.2006.00051.x

[25] Margaret Flemings, Shanzay Kazmi, Rachel Pak, and Orit Shaer. 2018. Crimson Wave: Shedding Light on Menstrual Health. In Proceedings of the Twelfth International Conference on Tangible, Embedded, and Embodied Interaction - TEI '18. ACM Press, Stockholm, Sweden, 343-348. DOI :

http://dx.doi.org/10.1145/3173225.3173292

[26] Sarah Fox, Noura Howell, Richmond Wong, and Franchesca Spektor. 2019. Vivewell: Speculating Near-Future Menstrual Tracking through Current Data Practices. In Proceedings of the 2019 on Designing Interactive Systems Conference - DIS '19. ACM Press, San Diego, CA, USA, 541-552. DOI : http://dx.doi.org/10.1145/3322276.3323695

[27] Sarah E. Fox, Rafael M.L. Silva, and Daniela K. Rosner. 2018. Beyond the Prototype: Maintenance, Collective Responsibility, and Public IoT. In Proceedings of the 2018 on Designing Interactive Systems Conference 2018 - DIS '18. ACM Press, Hong Kong, China, 21-32. D0I : http://dx.doi.org/10.1145/3196709.3196710

[28] Bill Gaver, Tony Dunne, and Elena Pacenti. 1999. Design: Cultural probes. interactions 6, 1 (Jan. 1999), 21-29. DOI : http://dx.doi.org/10.1145/291224.291235

[29] William Gaver. 2012. What should we expect from research through design?. In Proceedings of the 2012 ACM annual conference on Human Factors in Computing Systems - CHI'12. ACM Press, Austin, Texas, USA, 937. DOI : http://dx.doi.org/10.1145/2207676.2208538

[30] William W. Gaver, Jacob Beaver, and Steve Benford. 2003. Ambiguity As a Resource for Design. In
Proceedings of the SIGCHI Conference on Human Factors in Computing Systems (CHI '03). ACM, New York, NY, USA, 233-240. DOI : http://dx.doi.org/10.1145/642611.642653 event-place: Ft. Lauderdale, Florida, USA.

[31] M. Guida, M. Barbato, P. Bruno, G. Lauro, and C. Lampariello. 1993. Salivary ferning and the menstrual cycle in women. Clinical and Experimental Obstetrics \& Gynecology 20, 1 (1993), 48-54.

[32] Donna Haraway. 1988. Situated Knowledges: The Science Question in Feminism and the Privilege of Partial Perspective. Feminist Studies 14, 3 (1988), 575. DOI : http://dx.doi.org/10.2307/3178066

[33] Donna Haraway. 2008. When species meet. Number 3 in Posthumanities. University of Minnesota Press, Minneapolis. OCLC: ocn156975211.

[34] RI Henkin. 1974. Sensory changes during the menstrual cycle. (1974).

[35] Sarah Homewood. 2018a. Designing for the Changing Body: A Feminist Exploration of Self-Tracking Technologies. In Extended Abstracts of the 2018 CHI Conference on Human Factors in Computing Systems CHI '18. ACM Press, Montreal QC, Canada, 1-4. DOI : http://dx.doi.org/10.1145/3170427.3173031

[36] Sarah Homewood. 2018b. Reframing Design Problems Within Women's Health. DOI : http://dx.doi.org/10.21606/drs.2018.337

[37] Sarah Homewood. 2019. Inaction as a Design Decision: Reflections on Not Designing Self-Tracking Tools for Menopause. In Extended Abstracts of the 2019 CHI Conference on Human Factors in Computing Systems CHI EA '19. ACM Press, Glasgow, Scotland Uk, 1-12. DOI : http://dx.doi.org/10.1145/3290607.3310430

[38] Sarah Homewood, Harvey Bewley, and Laurens Boer. 2019. Ovum: Designing for Fertility Tracking as a Shared and Domestic Experience. In Proceedings of the 2019 on Designing Interactive Systems Conference DIS '19. ACM Press, San Diego, CA, USA, 553-565. DOI : http://dx.doi.org/10.1145/3322276.3323692

[39] Alexis Hope, Catherine D'Ignazio, Josephine Hoy, Rebecca Michelson, Jennifer Roberts, Kate Krontiris, and Ethan Zuckerman. 2019. Hackathons as Participatory Design: Iterating Feminist Utopias. In Proceedings of the 2019 CHI Conference on Human Factors in Computing Systems - CHI '19. ACM Press, Glasgow, Scotland Uk, 1-14. DOI :

http://dx.doi.org/10.1145/3290605.3300291

[40] Peter Händel and Johan Wahlström. 2019. Digital contraceptives based on basal body temperature measurements. Biomedical Signal Processing and Control 52 (July 2019), 141-151. DOI: http://dx.doi.org/10.1016/j.bspc.2019.04.019 
[41] Kristina Höök, Baptiste Caramiaux, Cumhur Erkut, Jodi Forlizzi, Nassrin Hajinejad, Michael Haller, Caroline Hummels, Katherine Isbister, Martin Jonsson, George Khut, Lian Loke, Danielle Lottridge, Patrizia Marti, Edward Melcer, Florian Müller, Marianne Petersen, Thecla Schiphorst, Elena Segura, Anna Ståhl, Dag Svanæs, Jakob Tholander, and Helena Tobiasson. 2018. Embracing First-Person Perspectives in Soma-Based Design. Informatics 5, 1 (Feb. 2018), 8. DOI : http://dx.doi.org/10.3390/informatics5010008

[42] Vaclav Insler, Herzel Melmed, Itzhak Eichenbrenner, David M. Serr, and Bruno Lunenfeld. 1972. The Cervical Score: A Simple Semiquantitative Method for Monitoring of the Menstrual Cycle. International Journal of Gynecology \& Obstetrics 10, 6 (Nov. 1972), 223-228. DOI :

http://dx.doi.org/10.1002/j.1879-3479.1972.tb00857.x

[43] Ingrid Johnston-Robledo and Joan C. Chrisler. 2013. The Menstrual Mark: Menstruation as Social Stigma. Sex Roles 68, 1-2 (Jan. 2013), 9-18. DOI : http://dx.doi.org/10.1007/s11199-011-0052-z

[44] Ilpo Kalevi Koskinen. 2012. Design research through practice from the lab, field, and showroom. Morgan Kaufmann/Elsevier, Waltham, MA. OCLC: 1030358463.

[45] Julia Kristeva. 1982. Powers of horror: an essay on abjection. Columbia University Press, New York.

[46] Stacey Kuznetsov, Cassandra Barrett, Piyum Fernando, and Kat Fowler. 2018. Antibiotic-Responsive Bioart: Exploring DIYbio as a Design Studio Practice. In Proceedings of the 2018 CHI Conference on Human Factors in Computing Systems - CHI'18. ACM Press, Montreal QC, Canada, 1-14. DOI :

http://dx.doi.org/10.1145/3173574.3174037

[47] Amanda Lazar, Norman Makoto Su, Jeffrey Bardzell, and Shaowen Bardzell. 2019. Parting the Red Sea: Sociotechnical Systems and Lived Experiences of Menopause. In Proceedings of the 2019 CHI Conference on Human Factors in Computing Systems - CHI '19. ACM Press, Glasgow, Scotland Uk, 1-16. DOI : http://dx.doi.org/10.1145/3290605.3300710

[48] Jen Liu, Daragh Byrne, and Laura Devendorf. 2018. Design for Collaborative Survival: An Inquiry into Human-Fungi Relationships. In Proceedings of the 2018 CHI Conference on Human Factors in Computing Systems - CHI '18. ACM Press, Montreal QC, Canada, 1-13. DOI : http://dx.doi.org/10.1145/3173574.3173614

[49] LOONCUP. 2015. The world's first SMART menstrual cup. (2015).

https://www.kickstarter.com/projects/700989404/ looncup-the-worlds-first-smart-menstrual-cup

[50] Laura U Marks. 2002. Touch: sensuous theory and multisensory media. University of Minnesota Press, Minneapolis. https://www.jstor.org/stable/10.5749/j.ctttv5n8 OCLC: 299511580.

[51] Joselyn McDonald, Siyan Zhao, Jen Liu, and Michael L. Rivera. 2018. MaxiFab: Applied Fabrication to Advance Period Technologies. In Proceedings of the 19th International ACM SIGACCESS Conference on Computers and Accessibility - DIS '18. ACM Press, Hong Kong, China, 13-19. DOI : http://dx.doi.org/10.1145/3197391.3205405

[52] Lydia Michie, Madeline Balaam, John McCarthy, Timur Osadchiy, and Kellie Morrissey. 2018. From Her Story, to Our Story: Digital Storytelling as Public Engagement around Abortion Rights Advocacy in Ireland. In Proceedings of the 2018 CHI Conference on Human Factors in Computing Systems - CHI '18. ACM Press, Montreal QC, Canada, 1-15. DOI :

http://dx.doi.org/10.1145/3173574.3173931

[53] Gabrielle Moss. 2019. The Complicated \& Fascinating History Behind The Sudden Rise Of Reusable Menstrual Products. (April 2019). https://www.bustle.com/p/whyare-menstrual-cups-so-popular-reusable-periodproducts-are-having-a-definitive-moment-17120105

[54] Manideepa Mukherjee. 2019. Challenges and opportunities of textile based smart sanitary napkin design. In Proceedings of the 2019 ACM International Joint Conference on Pervasive and Ubiquitous Computing and Proceedings of the 2019 ACM International Symposium on Wearable Computers UbiComp/ISWC '19. ACM Press, London, United Kingdom, 1044-1046. DOI:

http://dx.doi.org/10.1145/3341162.3349572

[55] my.Flow. 2019. my.Flow. (2019). http://www.trackmyflow.com/

[56] Dawn Nafus and Jamie Sherman. 2014. This One Does Not Go Up To Eleven: The Quantified Self Movement as an Alternative Big Data Practice. International Journal of Communication 8 (2014), 11.

[57] Carman Neustaedter and Phoebe Sengers. 2012. Autobiographical design in HCI research: designing and learning through use-it-yourself. In Proceedings of the Designing Interactive Systems Conference on - DIS '12. ACM Press, Newcastle Upon Tyne, United Kingdom, 514. DOI : http://dx.doi.org/10.1145/2317956.2318034

[58] Norma O’Flynn. 2006. Menstrual symptoms: the importance of social factors in women's experiences. The British Journal of General Practice 56, 533 (Dec. 2006), 950-957. https://www.ncbi.nlm.nih.gov/pmc/articles/PMC1934056/

[59] S. R. Pallone and G. R. Bergus. 2009. Fertility Awareness-Based Methods: Another Option for Family Planning. The Journal of the American Board of Family Medicine 22, 2 (March 2009), 147-157. DOI : http://dx.doi.org/10.3122/jabfm.2009.02.080038 
[60] María Puig de la Bellacasa. 2009. Touching technologies, touching visions. The reclaiming of sensorial experience and the politics of speculative thinking. Subjectivity 28, 1 (Sept. 2009), 297-315. DOI : http://dx.doi.org/10.1057/sub.2009.17

[61] Chella Quint. 2019. From embodied shame to reclaiming the stain: Reflections on a career in menstrual activism. The Sociological Review 67, 4 (July 2019), 927-942. DOI :

http://dx.doi.org/10.1177/0038026119854275

[62] Lauren Rosewarne. 2012. Periods in pop culture: menstruation in film and television. Lexington Books, Lanham, Md.

[63] Camilla Mørk Røstvik. 2018. Blood in the Shower: A Visual History of Menstruation and Clean Bodies. Visual Culture \& Gender 13 (Sept. 2018), 54-63. http://vcg.emitto.net/index.php/vcg/article/view/114

[64] Amy Slater and Marika Tiggemann. 2012. Time Since Menarche and Sport Participation as Predictors of Self-Objectification: A Longitudinal Study of Adolescent Girls. Sex Roles 67, 9-10 (Nov. 2012), 571-581. DOI :

http://dx.doi.org/10.1007/s11199-012-0200-0

[65] Anna Ståhl, Martin Jonsson, Johanna Mercurio, Anna Karlsson, Kristina Höök, and Eva-Carin Banka Johnson. 2016. The Soma Mat and Breathing Light. In Proceedings of the 2016 CHI Conference Extended Abstracts on Human Factors in Computing Systems CHI EA '16. ACM Press, San Jose, California, USA, 305-308. DOI : http://dx.doi.org/10.1145/2851581.2889464

[66] Marie Louise Juul Søndergaard. 2018. Staying with the Trouble through Design: Critical-feminist Design of Intimate Technology. Ph.D. Aarhus University. DOI : http://dx.doi.org/10.7146/aul.289.203

[67] Marie Louise Juul Søndergaard and Lone Koefoed Hansen. 2016. PeriodShare: A Bloody Design Fiction.
In Proceedings of the 9th Nordic Conference on Human-Computer Interaction - NordiCHI '16. ACM Press, Gothenburg, Sweden, 1-6. DOI : http://dx.doi.org/10.1145/2971485.2996748

[68] Marie Louise Juul Søndergaard and Lone Koefoed Hansen. 2018. Intimate Futures: Staying with the Trouble of Digital Personal Assistants through Design Fiction. In Proceedings of the 2018 on Designing Interactive Systems Conference 2018 - DIS '18. ACM Press, Hong Kong, China, 869-880. DOI : http://dx.doi.org/10.1145/3196709.3196766

[69] Giulia Tomasello. 2019. Future Flora. (2019). http://gitomasello.com/future-flora

[70] Agatha Tutia, Kelda Baljon, Lan Vu, and Daniela K. Rosner. 2019. HCI and Menopause: Designing With and Around the Aging Body. In Extended Abstracts of the 2019 CHI Conference on Human Factors in Computing Systems - CHI EA '19. ACM Press, Glasgow, Scotland Uk, 1-8. DOI : http://dx.doi.org/10.1145/3290607.3299066

[71] Jayne Wallace, John McCarthy, Peter C. Wright, and Patrick Olivier. 2013. Making design probes work. In Proceedings of the SIGCHI Conference on Human Factors in Computing Systems - CHI '13. ACM Press, Paris, France, 3441. DOI :

http://dx.doi.org/10.1145/2470654.2466473

[72] Jennifer Weiss-Wolf. 2017. Periods gone public: making a stand for menstrual equity. OCLC: 1002303038.

[73] Lisbeth Wikström-Frisén. 2016. Training and hormones in physically active women : with and without oral contraceptive use. (2016). http://urn.kb.se/resolve?urn= urn:nbn: se:umu: diva- 124842

[74] Charles Windlin, Pedro Sanches, Vasiliki Tsaknaki, Pavel Karpashevich, Madeline Balaam, and Kristina Höök. 2019. Soma Bits: Mediating technology to orchestrate bodily experiences. DOI :

http://dx.doi.org/10.6084/m9.figshare.7855799.v1 